\title{
Safety analysis of point supported glass curtain wall panels
}

\author{
PengDi ${ }^{1, a}$ ChenLongYu, ${ }^{2, b}$ \\ ${ }^{1}$ College of Architecture and Civil Engineering, Xi'an University of Science and Technology, Xi'an \\ 710054 ,China \\ ${ }^{2}$ College of Architecture and Civil Engineering, Xi'an University of Science and Technology, Xi'an \\ 710054,China \\ a532324179@qq.com, b846864533@qq.com
}

Keywords: point supported glass curtain wall, the support system, security

Abstract:Point supported glass curtain wall to show the permeability and integration structures inside and outside space, fully embodies the glass support system and the physical space of the artistic charm, but in appearance, but also brought great security risk. By analyzing the way the two-point supported glass curtain wall panel supporting system, using ANSYS two different glass curtain wall panel in the form of stress analysis, and discuss maximum stress two points of support in the form of a glass panel with glass thickness, center distance constraint points, and other factors affecting the constraints radius, two systems safety analysis of the glass curtain wall panel to engineering practice has a guiding role.

\section{Introduction}

The application of point supported glass curtain wall, which makes the space structure of light steel envelope in the technology and design, manufacture and installation technology, has the innovation, the technology content of building glass curtain wall project has been greatly improved, and the technology of curtain wall structure system is used in the glass curtain wall project, and the curtain wall is brought into the new development field ${ }^{[1]}$. Nowadays, the glass curtain wall structure has been questioned in the safety aspects, although the construction management department has been in the quality of glass curtain wall construction of the standard management, but the glass curtain wall engineering accident still occurs, this phenomenon should be caused by the engineering industry, especially in recent years, the connection of point type glass in glass curtain wall application. With the increase of the proportion of glass curtain wall used in public buildings, the safety of its structure must be paid more attention by the engineering designers. In this paper, two kinds of point supported glass curtain wall panels were analyzed, and the design and construction technology of the point supported glass curtain wall is enough.

\section{Finite element modeling analysis}

Glass curtain wall of point supported glass curtain wall: glass panel, supporting device and supporting system ${ }^{[2]}$. The glass panels are connected with the supporting system and the main structure by the connecting piece and the supporting system. The supporting system is the main bearing structure, which embodies the harmonious unity between the force and the United States, and it has a delicate decorative effect. Now, from the point of view of the safety of the structure, the glass panels of the two forms of analysis. 
The traditional point supported glass curtain wall is fixed by the opening of the glass panel and the supporting system is fixed on the building structure. Square glass panel now is $2000 \mathrm{~mm} *$ $2000 \mathrm{~mm}$, thickness $10 \mathrm{~mm}$, applied $1.2 \mathrm{KN} / \mathrm{m}^{2}$ in the vertical direction of surface $\left(1.2 \mathrm{E}-3 \mathrm{~N} / \mathrm{mm}^{2}\right)$ of the wind load, round four corner panel are respectively provided with a $36 \mathrm{~mm}$, the hole center from the plate edge distance is $100 \mathrm{~mm}$, the constraint in the $\mathrm{Z}$ direction perpendicular to the glass panel, and the the model of numerical simulation analysis, the panel is a symmetrical structure, now part of a comparative analysis of $1 / 4$ (see Figure 3 and Figure 4)

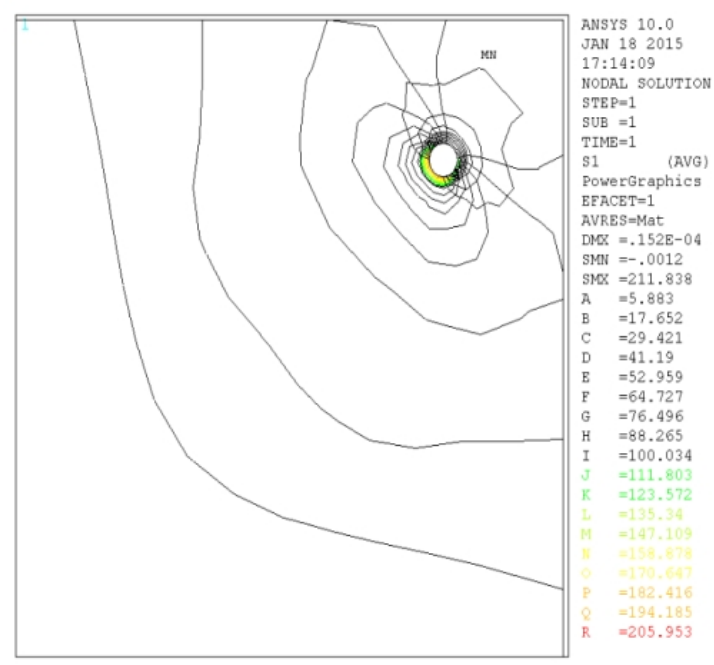

Figure 1Stress contour map of the main stress of the hole under the action of wind pressure

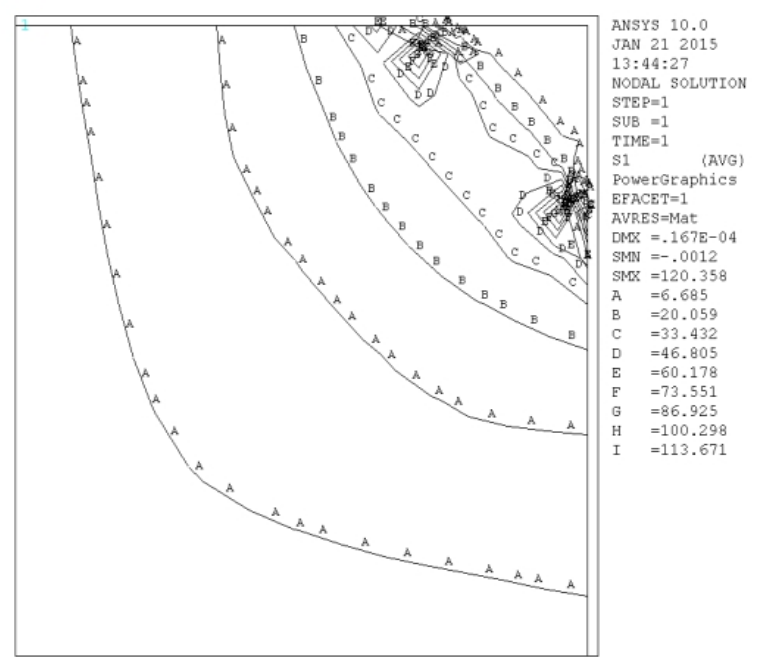

Figure 2Stress contour map of the main stress of the hole under the action of wind pressure

Through the finite element software for modeling analysis, we can clearly see from Figure 1 and figure 2, the main stress of the new structure of the point supported glass curtain wall panel is only the traditional point supported glass curtain wall panels, the new glass curtain wall panels is more secure, and the maximum stress of glass panels in the external wind load is not seen in the center and edge of glass panels ${ }^{[3]}$. Point supported glass curtain wall panel under load perpendicular to the plane of the glass curtain wall, glass plate bending, hole and constrained the main stress is much greater than in the center of the main stress value, namely the hole edge and the inner bound stress plays a leading role, but also easy to damage the site.

\section{Result analysis}

In point supported glass curtain wall structure system, the glass panels are fixed on the structural system. The glass panels are closely related to the connection form of glass panels under wind load. The maximum stress of the glass curtain wall panels with ANSYS is discussed, and the maximum stress of two kinds of point supported glass panels is discussed ${ }^{[4]}$.

\section{Effect of glass plate thickness on main stress}

Because of the traditional glass panel bearing form commonly used drilling and steel connections, the bearing capacity of the edge effect of opening of the glass panel will have a great impact, now support with new structure system, without the need for drilling of the glass panel, reduce the glass panel hole stress stress concentration effect on the whole glass panel the.

Two kinds of point supported glass curtain wall glass panels are analyzed by finite element method, and the model data is established, and the geometric size of the plate is $2000 \mathrm{~mm} *$ 2000mm;Modulus of elasticity: $\mathrm{E}=0.7 * 10^{5} \mathrm{MPa}$; Poisson's ratio: $\mu=0.24$;Density: $\rho=2.5 *$ 
$10^{-6} \mathrm{~kg} / \mathrm{mm}^{3}$; Applying $1.2 \mathrm{KN} / \mathrm{m}^{2}$ in the vertical direction of surface $\left(1.2 \mathrm{E}-3 \mathrm{~N} / \mathrm{mm}^{2}\right)$ of the wind load, round four corner panel are respectively provided with a $36 \mathrm{~mm}$, the hole center from the plate edge distance is $100 \mathrm{~mm}$, the constraint in the $\mathrm{Z}$ direction perpendicular to the glass panel, and the model of numerical simulation analysis.

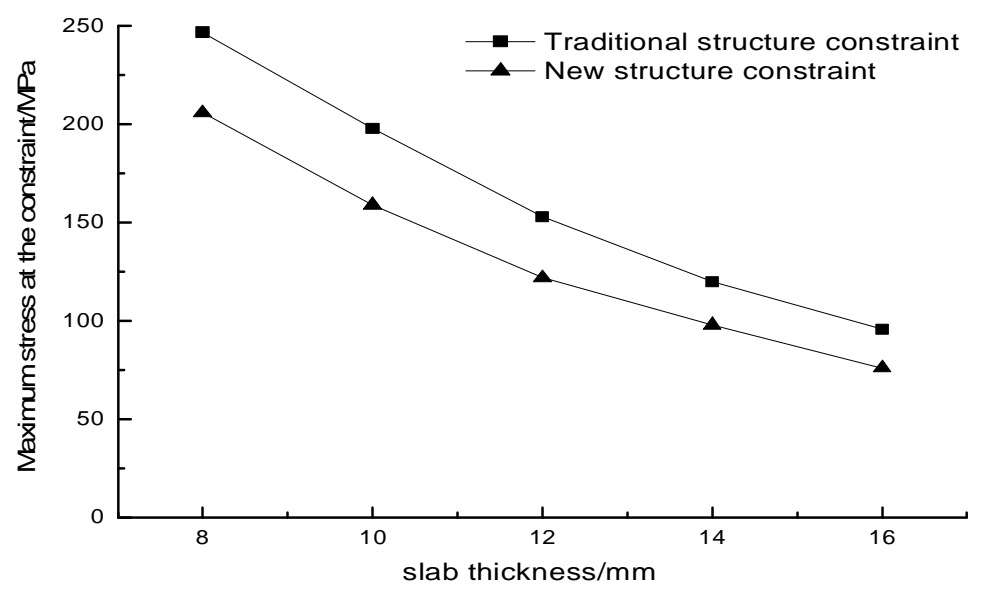

Figure 3 Slab thickness-Stress curve

From the results of 3 data, it can be seen that the maximum stress of glass panels with two kinds of different constrained structural forms is reduced, and the maximum stress of the new structure is always lower than that of the traditional structural constraint.

\section{Glass confinement center distance}

Point supported glass panels are influenced by the distance between the center of the glass and the edge of the glass. However, from the perspective of production and processing, with the increasing of the center distance of the constraint point, the weight of the metal connecting parts and fasteners used to connect the supporting structure of the glass panels are increasing, and the cost will be increased.

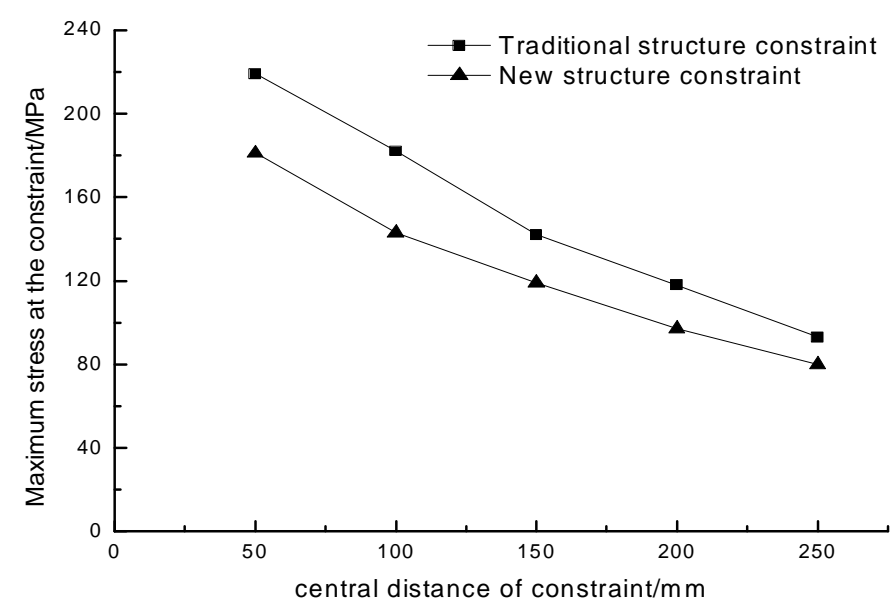

Figure 4 Central distance of constraint-Stress curve

From the results of Figure 4, it can be seen that, with the increasing of the center distance of the bound point, the maximum stress of the glass curtain wall in the constraint point is reduced, and the maximum stress of the traditional structure is always greater than the new structure. And when the center distance is greater than $100 \mathrm{~mm}$, the maximum stress of the constraint is decreased. 


\section{Glass confinement radius}

According to the law of elastic mechanics, the stress concentration will decrease with the increase of the diameter and the diameter of the glass panels.

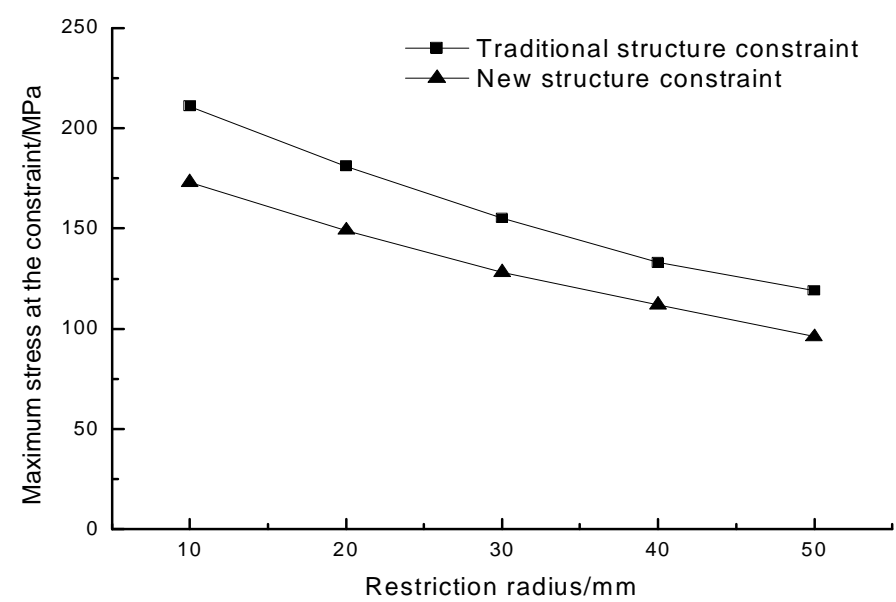

Figure 5Restriction radius-Stress curve

Through figure 5we can clearly see that the traditional structural form of point supported glass curtain wall panels with the increase of the open hole, the hole edge of the main stress value in the continuous decrease, and tend to be gentle. The new structure form of point supported glass curtain wall panels with the increase of the radius of the constraint, the maximum principal stress at the constraint will also be reduced. By comparing the two forms, we find that the new structure is always less than the maximum principal stress of the traditional structural constraint. But considering the security and the characteristics of the transparency, the larger the better, the more the influence of the radius of the constraint point can be studied.

\section{Conclusion}

In the practical engineering, with the increase of external load, the glass panel is the most easy to damage, should cause the attention of engineering construction, and with the increase of wind pressure, the main stress value will continue to increase, so the key parts of the strengthening is extremely important, should cause the attention of engineering construction.

The position of the constrained point has a great influence on the actual bearing capacity of glass panels. With the increasing of the center distance, the effect of an additional bending moment will be reduced, which will reduce the stress of glass panel center.

The research shows that the concentrated stress at the edge of the constraint point is changed with the increase of the thickness of the glass plate and the restriction radius.

\section{Reference}

[1] Technical specification for glass curtain wall engineering of 102-2003 [S] JGJ(In Chinese)

[2] Luo Yi. Building curtain wall design and construction. Beijing: Chemical Industry Press, (2011)(In Chinese)

[3] 50009-2012 GB building structure load code [S](In Chinese)

[4] Zhang Zhaohui.Ansys11.0 structural analysis of engineering examples analysis. Beijing: 
Mechanical Industry Press, (2008)(In Chinese)

[5] Zhang Qilin. Glass curtain wall structure design. Shanghai Tongji University press, (2007)(In Chinese) 